\title{
Review Article \\ Human Papillomavirus Infection, Infertility, and Assisted Reproductive Outcomes
}

\author{
Nigel Pereira, ${ }^{1}$ Katherine M. Kucharczyk, ${ }^{1}$ Jaclyn L. Estes, ${ }^{2}$ Rachel S. Gerber, \\ Jovana P. Lekovich, ${ }^{1}$ Rony T. Elias, ${ }^{1}$ and Steven D. Spandorfer ${ }^{1}$ \\ ${ }^{1}$ The Ronald O. Perelman and Claudia Cohen Center for Reproductive Medicine, Weill Cornell Medical College, \\ New York, NY 10021, USA \\ ${ }^{2}$ Department of Obstetrics and Gynecology, Weill Cornell Medical College, New York, NY 10021, USA \\ Correspondence should be addressed to Steven D. Spandorfer; sdspando@med.cornell.edu
}

Received 28 August 2015; Accepted 30 September 2015

Academic Editor: Cormac G. M. Gahan

Copyright (C) 2015 Nigel Pereira et al. This is an open access article distributed under the Creative Commons Attribution License, which permits unrestricted use, distribution, and reproduction in any medium, provided the original work is properly cited.

\begin{abstract}
The human papillomavirus (HPV) is a sexually transmitted infection common among men and women across all geographic and socioeconomic subgroups worldwide. Recent evidence suggests that HPV infection may affect fertility and alter the efficacy of assisted reproductive technologies. In men, HPV infection can affect sperm parameters, specifically motility. HPV-infected sperm can transmit viral DNA to oocytes, which may be expressed in the developing blastocyst. HPV can increase trophoblastic apoptosis and reduce the endometrial implantation of trophoblastic cells, thus increasing the theoretical risk of miscarriage. Vertical transmission of HPV during pregnancy may be involved in the pathophysiology of preterm rupture of membranes and spontaneous preterm birth. In patients undergoing intrauterine insemination for idiopathic infertility, HPV infection confers a lower pregnancy rate. In contrast, the evidence regarding any detrimental impact of HPV infection on IVF outcomes is inconclusive. It has been suggested that vaccination could potentially counter HPV-related sperm impairment, trophoblastic apoptosis, and spontaneous miscarriages; however, these conclusions are based on in vitro studies rather than large-scale epidemiological studies. Improvement in the understanding of HPV sperm infection mechanisms and HPV transmission into the oocyte and developing blastocyst may help explain idiopathic causes of infertility and miscarriage.
\end{abstract}

\section{Introduction}

The human papillomavirus (HPV) is one of the most common sexually transmitted viruses worldwide $[1,2]$. As recently as 1970, HPV was thought to be a single type that caused warty lesions at different tissue sites [3]. With the advent of recombinant DNA technology, however, it became evident that many different types of HPV existed, some of which were carcinogenic [3]. Current scientific literature tends to focus on HPV's association with cancer, particularly cervical cancer. However, infection with HPV is known to affect other aspects of human health as well. In fact, recent evidence suggests that HPV infection may affect fertility and alter the efficacy of assisted reproductive technologies $[4,5]$. The current review appraises the recent medical literature pertaining to the epidemiology, immunobiology, and impact of HPV infection on normal reproductive function. Furthermore, the paper critically evaluates the current evidence related to HPV infection and fertility alteration, as well as its impact on assisted reproductive pregnancy rates.

\section{Epidemiology}

Despite licensure of HPV vaccines in more than half of the world's countries, the global HPV prevalence was estimated at $12 \%$ in 2012 [6, 7]. Most recent data indicate that 14 million people are newly infected each year in the United States, with a total of 79 million people currently affected [8]. The virus's continuing prevalence is partially attributed to inconsistent vaccination rates $[9,10]$. The overall cost burden of preventing and treating HPV-associated disease in 2010 was estimated to be $\$ 8.0$ billion [11].

HPV infection is generally transmitted by skin-to-skin contact and infects the epithelial cells in genital mucosa, 
oral mucosa, or skin $[12,13]$. Most sexually active adults will acquire HPV in their lifetime [8], though it can occur at any age [14]. Some studies have shown a U-shaped curve with regards to $\mathrm{HPV}$ infection, meaning infection rates peak in women under the age of 30 and also in women aged 55-64 years [15]. In general, the risk of acquiring HPV increases with the number of recent and lifetime sexual partners $[8$, $16,17]$. Almost $40 \%$ of all women infected with human immunodeficiency virus (HIV) will also have coinfection with multiple HPV genotypes [18].

\section{Immunobiology of HPV}

HPV is a double-stranded nonenveloped DNA adenovirus, which belongs to a large family of more than 130 genotypes $[19,20]$. The genome of the virus can be divided into three main domains: a noncoding upstream regulatory region of $1 \mathrm{~kb}$ in size; an early region with six genes, namely, E6, E7, E1, E2, E4, and E5; and a late region with two genes, L1 (major capsid protein) and L2 (minor capsid protein) [17]. These viruses are generally classified as either low-risk types that cause benign warts or high-risk types that are associated with cancers [3]. While HPV 6 and 11 are the most common lowrisk types that cause anogenital warts, HPV 16 and 18 are the most common oncogenic or high-risk types, which are responsible for up to $70 \%$ of all cervical cancers worldwide $[21,22]$. The different types of papilloma viruses exhibit characteristic tropism: cutaneotropic (HPV 1, 4, 5, 8, 41, 48, 60,63 , and 65) types are isolated in cutaneous and plantar warts, whereas mucosotropic (HPV 6, 11, 13, 18, 39 44, 55, $16,31,33,35,52,58,67$, etc.) types are identified in benign and malignant lesions of the anogenital tract, oral cavity, oropharynx, and larynx.

The female genital tract faces high and frequent antigenic exposures [19]. Before reproductive age, numerous antigens are recognized as "self" or "own" commensal microbiota [19]. However, once sexual activity begins, the genital tract must deal with exposure to several other exogenous antigens, including those derived from the male reproductive tract [19]. From a biological perspective, HPV is a very successful pathogen; that is, it can induce chronic infections without any systemic symptoms, allowing the host to periodically shed large amounts of transmissible virus to naïve individuals [3]. The evasion of the immune system by HPV is primarily dependent on the differentiation of cell layers in the mucocutaneous epithelium [3]. Following microtrauma or abrasions to the epithelium, the basal cell layer is exposed and vulnerable to infection by HPV at low numbers [17]. Viral DNA replication ensues, increasing the number of genome copies to about 50-100 [17]. The dividing cells maintain copy numbers of the viral genome and at the same time tightly regulate the expression of the E6 and E7 proteins at very low levels $[3,17]$. When the host cells stop dividing and begin to differentiate into the upper layers of the epithelium [3], massive upregulation and replication of the viral genome occur (1000 copies per cell) along with abundant expression of the E6 and E7 proteins [17]. In the superficial layers of the epithelium, the L1 and L2 proteins are expressed and many thousand copies of infectious viral particles are assembled and shed [17]. This infectious cycle is completed in 2-3 weeks [17]. A large body of evidence suggests that oncogenic properties of high-risk HPV are related to the E6 and E7 proteins and their individual roles in disrupting the normal cell cycle of the host $[17,19]$.

Most HPV infections are subclinical and many present unnoticeable or mild symptoms [3, 19]. The incubation period of HPV ranges from 3 weeks to 8 months $[3,17]$. Approximately $10-30 \%$ of women have spontaneous regression of HPV infection in 3 months [17]; $90 \%$ of women are able to clear the HPV infection within 2 years $[3,19]$. The clearance of such infections occurs due to the development of cell-mediated immunity, accompanied by seroconversion and the antibody to the L1 major capsid protein [17]. A subset of women (10-15\%) do not mount a successful cellmediated immune response and they remain persistently infected [23]. These women remain at risk for developing high-grade disease and possibly cancer [24].

\section{HPV and Cancers}

HPV has been shown to play a key role in the development of various cancers [25]. Approximately 26,000 new HPV-related cancers (17,000 in women and 9,000 in men) are diagnosed in the United States annually [26]. The role of high-risk HPV in the malignant progression of cervical disease has now been known for over 30 years [27]. More recently [28], high-risk HPV has also been associated with cancers in anatomic locations such as head and neck [29, 30], oropharynx [31], lung [32, 33], and bladder [34]. Recent population-based studies in the United States have shown that $96 \%$ of cervical cancers, $93 \%$ of anal cancers, $64 \%$ of vaginal cancers, $51 \%$ of vulvar cancers, $36 \%$ of penile cancers, and $63 \%$ of oropharyngeal cancers are attributable to HPV $[8,25]$.

\section{HPV and Fertility}

It is widely accepted that sexually transmitted infections such as Chlamydia trachomatis, Neisseria gonorrhoeae, and Treponema pallidum can lead to alterations in fertility or even infertility [4]. Reproductive alterations have also been associated with sexually transmitted viruses, including HIV, cytomegalovirus, and herpes simplex virus [34, 35]. Recent data have also suggested HPV as a fertility-altering agent $[4,36]$. HPV infections can induce two different pathways: an infectious virion-producing pathway and a noninfectious cancer-producing pathway [37]. Evidence suggests that the former pathway may be involved in fertility alteration [37]. However, the role of HPV as a direct cause of infertility remains uncertain [38].

5.1. HPV and Sperm. It is well established that HPV infections in men can result in semen contamination [39-41]. Previous investigations have demonstrated the presence of HPV DNA and RNA in the penile shaft, urethra, epididymis, and testis $[42,43]$. In one study of 111 men whose intimate female partners were infected with HPV, HPV DNA was detected in the semen of $23.4 \%$ of men [44]. It is thought that HPV binds to 2 distinct sites along the equatorial 
TABLE 1: Summary of literature pertaining to the effect of HPV on fertility.

\begin{tabular}{|c|c|c|}
\hline Reference & Study type & Summary of findings \\
\hline \multicolumn{3}{|r|}{ Effect on sperm parameters } \\
\hline [47] & Systematic review & No effect on volume, viscosity, count, and morphology \\
\hline [50] & Original research & Enhanced motility; decreased velocity and amplitude of HPV-exposed sperm \\
\hline [51] & Original research & Enhanced motility, progression, and velocity in HPV-exposed sperm \\
\hline$[52,53]$ & Original research & Decreased sperm motility in HPV-infected men \\
\hline [54] & Systematic review & HPV-related impairment in sperm motility in men with idiopathic infertility \\
\hline [55] & Original research & Increase in DNA fragmentation \\
\hline [56] & Original research & Semen $\mathrm{pH}$ is borderline lower in HPV-positive men \\
\hline$[62-64]$ & Original research & $\begin{array}{c}\text { Effect on early embryogenesis } \\
\text { Increased DNA fragmentation and trophoblastic death in blastocysts }\end{array}$ \\
\hline \multicolumn{3}{|r|}{ Effect on early pregnancy } \\
\hline$[66-68]$ & Original research & HPV reduces the endometrial implantation of trophoblastic cells \\
\hline$[69,70]$ & Original research & HPV DNA is more frequently detected in spontaneous miscarriages compared to voluntary abortions \\
\hline$[71,72]$ & Original research & HPV infection in pregnancy may not confer a higher risk of miscarriage \\
\hline
\end{tabular}

region of the spermatozoon's head [45-47]. The presence of glycosaminoglycans or other soluble factors on the surface of the spermatozoon is believed to mediate the interaction and binding between HPV and sperm [45-47]. Recent evidence suggests that the L1 HPV capsid protein and glycosaminoglycan syndecan-1 colocalize in the equatorial region of the sperm head [48].

5.2. Effect on Sperm Parameters. In general, sexually transmitted infections may affect semen quality by inducing orchitis, epididymitis, urethritis, or urethral stickiness $[4,47]$. Yet the exact mechanisms by which HPV impairs sperm quality remain poorly understood. HPV infections in men can alter sperm motility $[48,49]$. In one study, investigators found enhanced motility along with decreased velocity and amplitude of lateral head displacement [50]. An independent group's work [51] confirmed the findings of enhanced motility, progression, and velocity in HPV-exposed sperm. The majority of studies, however, indicate decreased sperm motility in HPV-infected men [36, 46, 52, 53]. These findings remain consistent among infertile males and sperm donors. HPV-related impairment in sperm motility is frequently found in men with idiopathic infertility compared to healthy fertile controls [54]. HPV is also known to increase sperm DNA fragmentation [55] and induce changes in semen $\mathrm{pH}$ [56]. Other semen parameters such as volume, viscosity, count, and morphology are not different in HPV-infected and in noninfected semen samples [47].

5.3. Transmission of HPV and Early Embryogenesis. Initial studies showed that sperm could carry exogenous HPV DNA and could potentially act as a vector that transmits HPV to sexual partners, as well as to a fetus through fertilized oocytes [39, 57-59]. In mouse models, HPV-infected sperm successfully fertilized oocytes [60], followed by subsequent gene expression in the inner cell mass and trophectoderm of early blastocysts [61]. Using the hamster egg-human sperm penetration test, investigators similarly demonstrated that human sperm could transfer the E6/E7 genes and the L1 major capsid protein to oocytes, with gene expression resulting in developing blastocysts [48]. Following expression of the E6/E7 genes, increased DNA fragmentation and trophoblast death were noted in blastocysts [62-64]. These findings were particularly associated with the HPV 16 subtype $[63,64]$. The rate of HPV-related trophoblastic apoptosis seems to be related to the growth of the embryo; that is, the apoptosis rate is 3-fold and 5.8-fold greater at 3 and 12 days after fertilization, respectively [65]. It is important to note that the aforementioned findings are based on in vitro experiments in murine models, which may not necessarily reflect in vivo conditions in humans [36].

5.4. HPV and Early Pregnancy. In addition to its impact on trophoblastic growth, HPV seems to reduce the endometrial implantation of trophoblastic cells, thus increasing the theoretical risk of miscarriage [66-68]. In a study involving 108 patients with miscarriages, HPV 16 and 18 DNA was detected in $7.4 \%$ of all conceptuses tested [69]. In another study comparing 25 early miscarriages to 15 voluntary terminations of pregnancy, HPV E6/E7 sequences were detected in $60 \%$ of the former compared to $20 \%$ of the latter [70]. The finding that HPV DNA was detected more frequently in spontaneous miscarriages compared to voluntary abortions led to the consideration that HPV may be involved in the pathophysiology of early pregnancy loss [70]. Some studies have also indicated that exposure to HPV 6, 11, 16, or 18 in pregnancy can be associated with a $2.2 \%$ prevalence of major birth defects and a $1.5 \%$ risk of fetal death [68]. These findings, however, should be interpreted with caution, as they arise from retrospective or cross-sectional studies with small sample sizes. Contrary to these findings, at least 2 retrospective studies with larger study cohorts have shown that HPV infection in pregnancy may not confer a higher risk of miscarriage $[71,72]$. Table 1 summarizes the findings of the studies pertaining to the effect of HPV on fertility.

\section{HPV and Assisted Reproduction}

6.1. Intrauterine Insemination. The prevalence of HPV sperm infection is approximately $2-31 \%$ in the general population, 
TABLE 2: Summary of literature regarding the effect of HPV on assisted reproductive outcomes.

\begin{tabular}{|c|c|c|}
\hline Reference & Study type & Summary of findings \\
\hline \multicolumn{3}{|r|}{ Intrauterine insemination } \\
\hline$[46,47]$ & $\begin{array}{l}\text { Original research } \\
\text { Systematic review }\end{array}$ & HPV DNA may be associated with idiopathic asthenozoospermia \\
\hline [73] & Original research & $\begin{array}{l}\text { Women with HPV were six times less likely to become pregnant compared to women without the } \\
\text { infection }\end{array}$ \\
\hline \multicolumn{3}{|r|}{ In vitro fertilization } \\
\hline [5] & Original research & Women with HPV infection had a lower pregnancy rate compared to women without the infection \\
\hline [77] & Original research & $\begin{array}{l}\text { Higher odds of spontaneous miscarriage among women with HPV infection, as well as in women } \\
\text { whose male partners were HPV positive }\end{array}$ \\
\hline [78] & Original research & $\begin{array}{l}\text { No statistical difference in live birth rate when comparing HPV positive women compared to } \\
\text { negative controls }\end{array}$ \\
\hline$[38,79,80]$ & Original research & No effect of HPV on clinical pregnancy and spontaneous miscarriage rates \\
\hline
\end{tabular}

while the corresponding figure in men with unexplained infertility ranges between 10 and $35.7 \%$ [54]. In fact, some studies suggest that idiopathic asthenozoospermia may not have any risk factors except for the presence of HPV DNA $[46,47]$. In a recent retrospective study of 590 women undergoing 1529 intrauterine insemination (IUI) cycles [73], the authors reported an $11 \%$ prevalence of HPV per IUI cycle. Furthermore, women with HPV infection were six times less likely to become pregnant $(1.87 \%)$ compared to women without HPV infection (11.4\%).

6.2. In Vitro Fertilization. Women with subfertility or infertility eligible for in vitro fertilization (IVF) are known to have almost twice the rate of HPV-related abnormal cervical cytology or high-grade cervical lesions compared to the general population [74-76]. It is therefore necessary to assess the impact of HPV on IVF outcome, if any. In one of the earliest studies evaluating the impact of HPV on IVF outcomes [5], the investigators detected HPV in $16 \%$ of their study cohort of 106 patients. Although no difference was found in the number of oocytes retrieved, number of embryos transferred, embryo quality, or spontaneous miscarriage rates, women with HPV infection had a lower pregnancy rate $(23.5 \%)$ compared to women without HPV infection (57.0\%). In another study of 199 infertile couples, 9.5\%, 17.5\%, and 4.5\% of males, females, and both partners were found to be HPV positive, respectively [77]. The authors reported higher odds of spontaneous miscarriage (odds ratio: 4.20) among women with HPV infection, as well as in women whose male partners were HPV positive (odds ratio: 11.3). A different group of investigators noted lower birth rates in HPV positive women compared to negative controls, though these differences were not statistically different owing to a small sample size [78]. However, subsequent studies have shown conflicting results, with at least 3 studies showing no effect of HPV on clinical pregnancy and spontaneous miscarriage rates after IVF [38, $79,80]$. Table 2 summarizes the literature regarding the effect of HPV on assisted reproductive outcomes.

\section{HPV and Adverse Pregnancy Outcomes}

The detection of HPV in placental tissue suggests vertical transmission of HPV $[59,67]$. In a study of 291 pregnant women of $>36$ weeks of gestation, the rate of vertical transmission was estimated to be $18.2 \%$ [81]. Vertical transmission was often noted when an infant was delivered through an infected cervix; however, the absence of HPV infection in all infants at 6 months suggested temporary inoculation rather than a vertical infection [81]. Despite only transient detection of HPV DNA, there is speculation that HPV may play a possible role in adverse pregnancy outcomes. Recent evidence suggests that HPV, at least in part, is associated with preterm rupture of membranes $[82,83]$ and spontaneous preterm birth [84-86].

\section{HPV Vaccination}

Currently, the HPV vaccine is approved for prevention of genital warts, cervical dysplasia, and cervical cancer $[3,20]$. Given the emerging association of HPV infection with other malignancies as well as fertility alteration, such a vaccine could help reduce HPV-related disease burden. The primary rationale for utilizing HPV vaccines would be to counter any HPV-related sperm impairment in couples with idiopathic infertility [66]. Furthermore, from a theoretical standpoint, the HPV vaccination could prevent HPV-related trophoblastic apoptosis and spontaneous miscarriages, thereby improving assisted reproductive outcomes [66]. HPV infection of sperm is also a large-scale problem for sperm donor banks $[87,88]$. In the absence of effective sperm washing procedures that are able to eliminate HPV infection, male vaccination can be considered a possible strategy for the prevention of HPV-related sperm impairment in donors [66]. Although the aforementioned strategies seem reasonable, it must be noted that these suggestions are based on in vitro studies rather than large-scale epidemiological studies.

\section{Conclusions}

The human papillomavirus (HPV) is a ubiquitous sexually transmitted infection, which often goes undiagnosed. Nevertheless, its wide prevalence has helped uncover some of the negative ramifications of infection with the virus. Although HPV is most widely known for its link to various cancers, recent evidence also suggests an association with infertility 
and adverse pregnancy outcomes. Regarding fertility, HPV seems to affect both men and women-the virus can bind to the head of a spermatozoon and reduce sperm motility in men and may reduce the endometrial implantation of trophoblastic cells in women. Blastocysts that resulted from HPV-infected sperm were found to have expression of HPVrelated genes with corresponding trophoblastic apoptosis. The role of HPV in the success of assisted reproduction is less clear-cut; several studies show a decreased pregnancy rate for intrauterine insemination and in vitro fertilization in women with HPV compared to controls, while other studies show no correlation. HPV has also been linked with preterm rupture of membranes, spontaneous preterm birth, and a potentially increased rate of early pregnancy loss. Given the wide impact of the virus on human health, vaccination of men and women will be vital to the reduction of disease burden on future patients.

\section{Conflict of Interests}

The authors declare that there is no conflict of interests regarding the publication of this paper.

\section{References}

[1] S. R. Pagliusi and M. T. Aguado, "Efficacy and other milestones for human papillomavirus vaccine introduction," Vaccine, vol. 23, no. 5, pp. 569-578, 2004.

[2] S. R. Pagliusi and S. M. Garland, "International standard reagents for HPV detection," Disease Markers, vol. 23, no. 4, pp. 283-296, 2007.

[3] M. Stanley, "Immunobiology of HPV and HPV vaccines," Gynecologic Oncology, vol. 109, supplement 2, pp. S15-S21, 2008.

[4] T. Souho, M. Benlemlih, B. Bennani, and D. M. Harper, "Human papillomavirus infection and fertility alteration: a systematic review," PLoS ONE, vol. 10, no. 5, Article ID e0126936, 2015.

[5] S. D. Spandorfer, A. M. Bongiovanni, S. Fasioulotis, Z. Rosenwaks, W. J. Ledger, and S. S. Witkin, "Prevalence of cervical human papillomavirus in women undergoing in vitro fertilization and association with outcome," Fertility and Sterility, vol. 86, no. 3, pp. 765-767, 2006.

[6] L. E. Markowitz, V. Tsu, S. L. Deeks et al., "Human papillomavirus vaccine introduction-the first five years," Vaccine, vol. 30, supplement 5, pp. F139-F148, 2012.

[7] A. S. Noronha, L. E. Markowitz, and E. F. Dunne, "Systematic review of human papillomavirus vaccine coadministration," Vaccine, vol. 32, no. 23, pp. 2670-2674, 2014.

[8] E. F. Dunne, L. E. Markowitz, M. Saraiya et al., "CDC grand rounds: reducing the burden of HPV-associated cancer and disease," Morbidity and Mortality Weekly Report, vol. 63, no. 4, pp. 69-72, 2014.

[9] A. Jemal, E. P. Simard, C. Dorell et al., "Annual report to the nation on the status of cancer, 1975-2009, featuring the burden and trends in human papillomavirus (HPV)-associated cancers and HPV vaccination coverage levels," Journal of the National Cancer Institute, vol. 105, no. 3, pp. 175-201, 2013.

[10] P. Jeudin, E. Liveright, M. G. Del Carmen, and R. B. Perkins, "Race, ethnicity, and income factors impacting human papillomavirus vaccination rates," Clinical Therapeutics, vol. 36, no. 1 , pp. 24-37, 2014.
[11] H. W. Chesson, D. U. Ekwueme, M. Saraiya, M. Watson, D. R. Lowy, and L. E. Markowitz, "Estimates of the annual direct medical costs of the prevention and treatment of disease associated with human papillomavirus in the United States," Vaccine, vol. 30, no. 42, pp. 6016-6019, 2012.

[12] X. Castellsagué, "Natural history and epidemiology of HPV infection and cervical cancer," Gynecologic Oncology, vol. 110, supplement 2, no. 3, pp. S4-S7, 2008.

[13] S. K. Kjaer, B. Chackerian, A. J. C. van den Brule et al., "Highrisk human papillomavirus is sexually transmitted: evidence from a follow-up study of virgins starting sexual activity (intercourse)," Cancer Epidemiology Biomarkers and Prevention, vol. 10, no. 2, pp. 101-106, 2001.

[14] A. Antonsson, S. Karanfilovska, P. G. Lindqvist, and B. G. Hansson, "General acquisition of human papillomavirus infections of skin occurs in early infancy," Journal of Clinical Microbiology, vol. 41, no. 6, pp. 2509-2514, 2003.

[15] N. Muñoz, F. Méndez, H. Posso et al., "Incidence, duration, and determinants of cervical human papillomavirus infection in a cohort of Colombian women with normal cytological results," Journal of Infectious Diseases, vol. 190, no. 12, pp. 2077-2087, 2004.

[16] S. Vaccarella, R. Herrero, M. Dai et al., "Reproductive factors, oral contraceptive use, and human papillomavirus infection: pooled analysis of the IARC HPV prevalence surveys," Cancer Epidemiology Biomarkers and Prevention, vol. 15, no. 11, pp. 2148-2153, 2006.

[17] M. Stanley, "Pathology and epidemiology of HPV infection in females," Gynecologic Oncology, vol. 117, supplement 2, pp. S5S10, 2010.

[18] G. M. Clifford, M. A. G. Gonçalves, and S. Franceschi, "Human papillomavirus types among women infected with HIV: a metaanalysis," AIDS, vol. 20, no. 18, pp. 2337-2344, 2006.

[19] R. Garcia-Chacon, S. F. Velasco-Ramirez, L. Flores-Romo, and A. Daneri-Navarro, "Immunobiology of HPV infection," Archives of Medical Research, vol. 40, no. 6, pp. 443-448, 2009.

[20] M. Stanley, L. Gissmann, and D. Nardelli-Haefliger, "Immunobiology of human papillomavirus infection and vaccinationimplications for second generation vaccines," Vaccine, vol. 26, supplement 10, pp. K62-K67, 2008.

[21] Committee on Practice Bulletins-Gynecology, "ACOG practice bulletin number 131: screening for cervical cancer," Obstetrics \& Gynecology, vol. 120, no. 5, pp. 1222-1238, 2012.

[22] D. Saslow, D. Solomon, H. W. Lawson et al., "American Cancer Society, American Society for Colposcopy and Cervical Pathology, and American Society for Clinical Pathology screening guidelines for the prevention and early detection of cervical cancer," American Journal of Clinical Pathology, vol. 137, no. 4, pp. 516-542, 2012.

[23] K. S. Cuschieri, H. A. Cubie, M. W. Whitley et al., "Persistent high risk HPV infection associated with development of cervical neoplasia in a prospective population study," Journal of Clinical Pathology, vol. 58, no. 9, pp. 946-950, 2005.

[24] K.-L. Liaw, A. Hildesheim, R. D. Burk et al., "A prospective study of human papillomavirus (HPV) type 16 DNA detection by polymerase chain reaction and its association with acquisition and persistence of other HPV types," The Journal of Infectious Diseases, vol. 183, no. 1, pp. 8-15, 2001.

[25] C. Cobos, J. A. Figueroa, L. Mirandola et al., "The role of Human Papilloma Virus (HPV) infection in non-anogenital cancer and 
the promise of immunotherapy: a review," International Reviews of Immunology, vol. 33, no. 5, pp. 383-401, 2014.

[26] CDC, Human Papillomavirus (HPV)-Associated Cancers, US Department of Health and Human Services, CDC, Atlanta, Ga, USA, 2013, http://www.cdc.gov/cancer/hpv/statistics/cases.htm.

[27] D. P. Zandberg, R. Bhargava, S. Badin, and K. J. Cullen, "The role of human papillomavirus in nongenital cancers," CA: A Cancer Journal for Clinicians, vol. 63, no. 1, pp. 57-81, 2013.

[28] C. Fakhry, W. H. Westra, S. Li et al., "Improved survival of patients with human papillomavirus-positive head and neck squamous cell carcinoma in a prospective clinical trial," Journal of the National Cancer Institute, vol. 100, no. 4, pp. 261-269, 2008.

[29] C. C. R. Ragin and E. Taioli, "Survival of squamous cell carcinoma of the head and neck in relation to human papillomavirus infection: review and meta-analysis," International Journal of Cancer, vol. 121, no. 8, pp. 1813-1820, 2007.

[30] K. K. Ang, J. Harris, R. Wheeler et al., "Human papillomavirus and survival of patients with oropharyngeal cancer," The New England Journal of Medicine, vol. 363, no. 1, pp. 24-35, 2010.

[31] M. Srinivasan, E. Taioli, and C. C. Ragin, "Human papillomavirus type 16 and 18 in primary lung cancers-a metaanalysis," Carcinogenesis, vol. 30, no. 10, pp. 1722-1728, 2009.

[32] M. Ciotti, L. Giuliani, V. Ambrogi et al., "Detection and expression of human papillomavirus oncogenes in non-small cell lung cancer," Oncology Reports, vol. 16, no. 1, pp. 183-189, 2006.

[33] A. M. Aglianò, A. Gradilone, P. Gazzaniga et al., "High frequency of human papillomavirus detection in urinary bladder cancer," Urologia Internationalis, vol. 53, no. 3, pp. 125-129, 1994.

[34] N. Kapranos, E. Petrakou, C. Anastasiadou, and D. Kotronias, "Detection of herpes simplex virus, cytomegalovirus, and Epstein-Barr virus in the semen of men attending an infertility clinic," Fertility and Sterility, vol. 79, supplement 3, pp. 15661570, 2003.

[35] B. G. Bachir and K. Jarvi, "Infectious, inflammatory, and immunologic conditions resulting in male infertility," Urologic Clinics of North America, vol. 41, no. 1, pp. 67-81, 2014.

[36] S. Gizzo, B. Ferrari, M. Noventa et al., "Male and couple fertility impairment due to HPV-DNA sperm infection: update on molecular mechanism and clinical impact-systematic review," BioMed Research International, vol. 2014, Article ID 230263, 12 pages, 2014.

[37] C. E. Depuydt, A. M. Criel, I. H. Benoy, M. Arbyn, A. J. Vereecken, and J. J. Bogers, "Changes in type-specific human papillomavirus load predict progression to cervical cancer," Journal of Cellular and Molecular Medicine, vol. 16, no. 12, pp. 3096-3104, 2012.

[38] R. Schillaci, G. Capra, C. Bellavia et al., "Detection of oncogenic human papillomavirus genotypes on spermatozoa from male partners of infertile couples," Fertility and Sterility, vol. 100, no. 5, pp. 1236-1240, 2013.

[39] Y. M. Lai, F.-P. Yang, and C. C. Pao, "Human papillomavirus deoxyribonucleic acid and ribonucleic acid in seminal plasma and sperm cells," Fertility and Sterility, vol. 65, no. 5, pp. 10261030, 1996.

[40] O. Olatunbosun, H. Deneer, and R. Pierson, "Human papillomavirus DNA detection in sperm using polymerase chain reaction," Obstetrics and Gynecology, vol. 97, no. 3, pp. 357-360, 2001.
[41] G. Bezold, J. A. Politch, N. B. Kiviat, J. M. Kuypers, H. Wolff, and D. J. Anderson, "Prevalence of sexually transmissible pathogens in semen from asymptomatic male infertility patients with and without leukocytospermia," Fertility and Sterility, vol. 87, no. 5, pp. 1087-1097, 2007.

[42] C. M. Nielson, R. Flores, R. B. Harris et al., "Human papillomavirus prevalence and type distribution in male anogenital sites and semen," Cancer Epidemiology Biomarkers and Prevention, vol. 16, no. 6, pp. 1107-1114, 2007.

[43] C. M. Nielson, R. B. Harris, R. Flores et al., "Multiple-type human papillomavirus infection in male anogenital sites: prevalence and associated factors," Cancer Epidemiology Biomarkers and Prevention, vol. 18, no. 4, pp. 1077-1083, 2009.

[44] O. Aynaud, J.-D. Poveda, B. Huynh, A. Guillemotonia, and R. Barrasso, "Frequency of herpes simplex virus, cytomegalovirus and human papillomavirus DNA in semen," International Journal of STD and AIDS, vol. 13, no. 8, pp. 547-550, 2002.

[45] J. Pérez-Andino, C. B. Buck, and K. Ribbeck, "Adsorption of human papillomavirus 16 to live human sperm," PLOS ONE, vol. 4, no. 6, Article ID e5847, 2009.

[46] C. Foresta, A. Garolla, D. Zuccarello et al., "Human papillomavirus found in sperm head of young adult males affects the progressive motility," Fertility and Sterility, vol. 93, no. 3, pp. 802-806, 2010.

[47] A. Garolla, D. Pizzol, and C. Foresta, "The role of human papillomavirus on sperm function," Current Opinion in Obstetrics and Gynecology, vol. 23, no. 4, pp. 232-237, 2011.

[48] C. Foresta, C. Patassini, A. Bertoldo et al., "Mechanism of human papillomavirus binding to human spermatozoa and fertilizing ability of infected spermatozoa," PLoS ONE, vol. 6, no. 3, Article ID e15036, 2011.

[49] Y. M. Lai, Y. K. Soong, J. F. Lee, F.-P. Yang, H. Y. Huang, and C. C. Pao, "The effect of human papillomavirus infection on sperm cell motility," Fertility and Sterility, vol. 67, no. 6, pp. 1152-1155, 1997.

[50] D. A. Connelly, P. J. Chan, W. C. Patton, and A. King, "Human sperm deoxyribonucleic acid fragmentation by specific types of papillomavirus," American Journal of Obstetrics \& Gynecology, vol. 184, no. 6, pp. 1068-1070, 2001.

[51] J. E. Brossfield, P. J. Chan, W. C. Patton, and A. King, “Tenacity of exogenous human papillomavirus DNA in sperm washing," Journal of Assisted Reproduction and Genetics, vol. 16, no. 6, pp. 325-328, 1999.

[52] A. Garolla, A. Lenzi, G. Pal et al., "Human papillomavirus sperm infection and assisted reproduction: a dangerous hazard with a possible safe solution," Human Reproduction, vol. 27, no. 4, pp. 967-973, 2012.

[53] C. Foresta, D. Pizzol, A. Moretti, L. Barzon, G. Pal, and A. Garolla, "Clinical and prognostic significance of human papillomavirus DNA in the sperm or exfoliated cells of infertile patients and subjects with risk factors," Fertility and Sterility, vol. 94, no. 5, pp. 1723-1727, 2010.

[54] C. Foresta, M. Noventa, L. De Toni, S. Gizzo, and A. Garolla, "HPV-DNA sperm infection and infertility: from a systematic literature review to a possible clinical management proposal," Andrology, vol. 3, no. 2, pp. 163-173, 2015.

[55] C. A. Lee, C. T. F. Huang, A. King, and P. J. Chan, "Differential effects of human papillomavirus DNA types on p53 tumorsuppressor gene apoptosis in sperm," Gynecologic Oncology, vol. 85, no. 3, pp. 511-516, 2002. 
[56] M. A. M. Rintala, S. E. Grénman, P. P. Pöllänen, J. J. O. Suominen, and S. M. Syrjänen, "Detection of high-risk HPV DNA in semen and its association with the quality of semen," International Journal of STD and AIDS, vol. 15, no. 11, pp. 740743, 2004.

[57] P. J. Chan, B. C. Su, T. Kalugdan, I. M. Seraj, D. R. Tredway, and A. King, "Human papillomavirus gene sequences in washed human sperm deoxyribonucleic acid," Fertility and Sterility, vol. 61, no. 5, pp. 982-985, 1994.

[58] P. J. Chan, T. Kalugdan, B. C. Su et al., "Sperm as a noninvasive gene delivery system for preimplantation embryos," Fertility and Sterility, vol. 63, no. 5, pp. 1121-1124, 1995.

[59] R. L. Rombaldi, E. P. Serafini, J. Mandelli, E. Zimmermann, and K. P. Losquiavo, "Transplacental transmission of human papillomavirus," Virology Journal, vol. 5, article 106, 2008.

[60] P. J. Chan, B. C. Su, D. R. Tredway, M. Seraj, I. M. Seraj, and A. King, "Uptake of exogenous human papilloma virus 11 DNA by oocytes and detection by the polymerase chain reaction," Journal of Assisted Reproduction and Genetics, vol. 9, no. 6, pp. 531-533, 1992.

[61] M. Cabrera, P. J. Chan, T. H. Kalugdan, and A. King, "Transfection of the inner cell mass and lack of a unique DNA sequence affecting the uptake of exogenous DNA by sperm as shown by dideoxy sequencing analogues," Journal of Assisted Reproduction and Genetics, vol. 14, no. 2, pp. 120-124, 1997.

[62] H. You, Y. Liu, M. J. Carey, C. L. Lowery, and P. L. Hermonat, "Defective 3A trophoblast-endometrial cell adhesion and altered $3 \mathrm{~A}$ growth and survival by human papillomavirus type 16 oncogenes," Molecular Cancer Research, vol. 1, no. 1, pp. 25-31, 2002.

[63] J. H. Calinisan, S. R. Chan, A. King, and P. J. Chan, "Human papillomavirus and blastocyst apoptosis," Journal of Assisted Reproduction and Genetics, vol. 19, no. 3, pp. 132-136, 2002.

[64] A. A. Henneberg, W. C. Patton, J. D. Jacobson, and P. J. Chan, "Human papilloma virus DNA exposure and embryo survival is stage-specific," Journal of Assisted Reproduction and Genetics, vol. 23, no. 6, pp. 255-259, 2006.

[65] L. M. Gomez, Y. Ma, C. Ho, C. M. McGrath, D. B. Nelson, and S. Parry, "Placental infection with human papillomavirus is associated with spontaneous preterm delivery," Human Reproduction, vol. 23, no. 3, pp. 709-715, 2008.

[66] M. Noventa, A. Andrisani, S. Gizzo, G. B. Nardelli, and G. Ambrosini, "Is it time to shift the attention on early stages embryo development to avoid inconclusive evidence on HPVrelated infertility: debate and proposal," Reproductive Biology and Endocrinology, vol. 12, article 48, 2014.

[67] W. Eppel, C. Worda, P. Frigo, M. Ulm, E. Kucera, and K. Czerwenka, "Human papillomavirus in the cervix and placenta," Obstetrics and Gynecology, vol. 96, no. 3, pp. 337-341, 2000.

[68] M. Matovina, K. Husnjak, N. Milutin, S. Ciglar, and M. Grce, "Possible role of bacterial and viral infections in miscarriages," Fertility and Sterility, vol. 81, no. 3, pp. 662-669, 2004.

[69] L. J. Hong, B. T. Oshiro, and P. J. Chan, "HPV-16 exposed mouse embryos: a potential model for pregnancy wastage," Archives of Gynecology and Obstetrics, vol. 287, no. 6, pp. 1093-1097, 2013.

[70] P. L. Hermonat, L. Han, P. J. Wendel et al., "Human papillomavirus is more prevalent in first trimester spontaneously aborted products of conception compared to elective specimens," Virus Genes, vol. 14, no. 1, pp. 13-17, 1997.

[71] M. Skoczyński, A. Goździcka-Józefiak, and A. Kwaśniewska, "Prevalence of human papillomavirus in spontaneously aborted products of conception," Acta Obstetricia et Gynecologica Scandinavica, vol. 90, no. 12, pp. 1402-1405, 2011.

[72] L. Conde-Ferráez, A. D. A. Chan May, J. R. Carrillo-Martínez, G. Ayora-Talavera, and M. D. R. González-Losa, "Human papillomavirus infection and spontaneous abortion: a case-control study performed in Mexico," European Journal of Obstetrics Gynecology and Reproductive Biology, vol. 170, no. 2, pp. 468473, 2013.

[73] C. E. Depuydt, L. Verstraete, M. Berth et al., "Human papillomavirus positivity in women undergoing intrauterine insemination has a negative effect on pregnancy rates," Gynecologic and Obstetric Investigation, 2015.

[74] D. van Hamont, L. H. C. Nissen, A. G. Siebers et al., "Abnormal cervical cytology in women eligible for IVF," Human Reproduction, vol. 21, no. 9, pp. 2359-2363, 2006.

[75] B. Abdullgaffar, M. O. Kamal, and A. Hasoub, "The prevalence of abnormal cervical cytology in women with infertility," Diagnostic Cytopathology, vol. 38, no. 11, pp. 791-794, 2010.

[76] H. Tanaka, A. Karube, H. Kodama, J. Fukuda, and T. Tanaka, "Mass screening for human papillomavirus type 16 infection in infertile couples," The Journal of Reproductive Medicine, vol. 45, no. 11, pp. 907-911, 2000.

[77] A. Perino, L. Giovannelli, R. Schillaci et al., "Human papillomavirus infection in couples undergoing in vitro fertilization procedures: impact on reproductive outcomes," Fertility and Sterility, vol. 95, no. 5, pp. 1845-1848, 2011.

[78] M. Comar, L. Monasta, N. Zanotta, L. Vecchi Brumatti, G. Ricci, and G. Zauli, "Human papillomavirus infection is associated with decreased levels of GM-CSF in cervico-vaginal fluid of infected women," Journal of Clinical Virology, vol. 58, no. 2, pp. 479-481, 2013.

[79] Y. Wang, C. Wang, J. Qiao, L. Wang, and S. Liang, "Relationship of cytopathology and cervical infection to outcome of invitro fertilization and embryo transfer," International Journal of Gynecology and Obstetrics, vol. 101, no. 1, pp. 21-26, 2008.

[80] R. Yang, Y. Wang, J. Qiao, P. Liu, L. Geng, and Y.-L. Guo, "Does human papillomavirus infection do harm to in-vitro fertilization outcomes and subsequent pregnancy outcomes?" Chinese Medical Journal, vol. 126, no. 4, pp. 683-687, 2013.

[81] H. Park, S. W. Lee, I. H. Lee et al., "Rate of vertical transmission of human papillomavirus from mothers to infants: relationship between infection rate and mode of delivery," Virology Journal, vol. 9, article 80, 2012.

[82] G. Cho, K.-J. Min, H.-R. Hong et al., "High-risk human papillomavirus infection is associated with premature rupture of membranes," BMC Pregnancy and Childbirth, vol. 13, article 173, 2013.

[83] U. Bonde, J. S. Joergensen, O. Mogensen, and R. F. Lamont, "The potential role of HPV vaccination in the prevention of infectious complications of pregnancy," Expert Review of Vaccines, vol. 13, no. 11, pp. 1307-1316, 2014.

[84] Z. Zuo, S. Goel, and J. E. Carter, "Association of cervical cytology and HPV DNA status during pregnancy with placental abnormalities and preterm birth," American Journal of Clinical Pathology, vol. 136, no. 2, pp. 260-265, 2011.

[85] J. N. Hong, E. K. Berggren, S. L. Campbell, J. S. Smith, and L. Rahangdale, "Abnormal cervical cancer screening in pregnancy and preterm delivery," Paediatric and Perinatal Epidemiology, vol. 28, no. 4, pp. 297-301, 2014. 
[86] Q.-T. Huang, M. Zhong, Y.-F. Gao et al., "Can HPV vaccine have other health benefits more than cancer prevention? A systematic review of association between cervical HPV infection and preterm birth," Journal of Clinical Virology, vol. 61, no. 3, pp. 321328, 2014.

[87] C. Foresta, D. Pizzol, A. Bertoldo, M. Menegazzo, L. Barzon, and A. Garolla, "Semen washing procedures do not eliminate human papilloma virus sperm infection in infertile patients," Fertility and Sterility, vol. 96, no. 5, pp. 1077-1082, 2011.

[88] M. D. Kaspersen, P. B. Larsen, H. J. Ingerslev et al., "Identification of multiple HPV types on spermatozoa from human sperm donors," PLoS ONE, vol. 6, no. 3, Article ID e18095, 2011. 


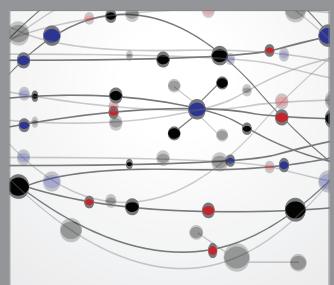

The Scientific World Journal
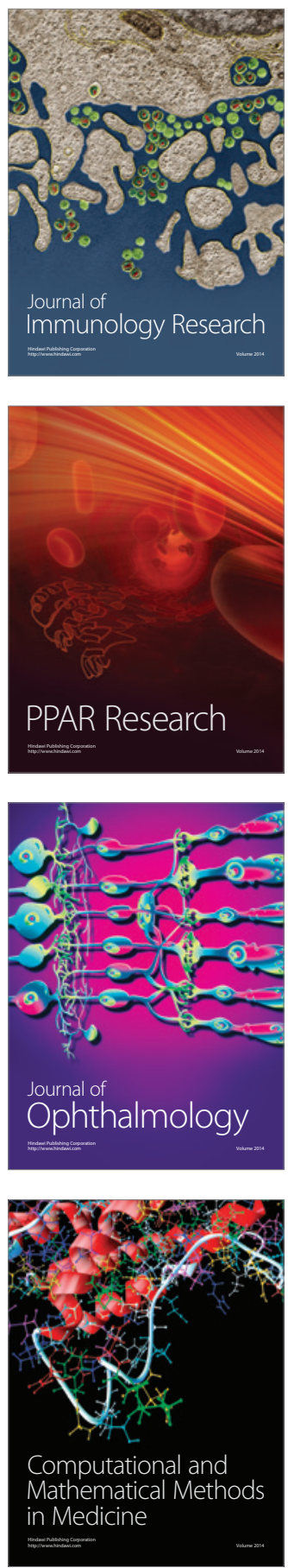

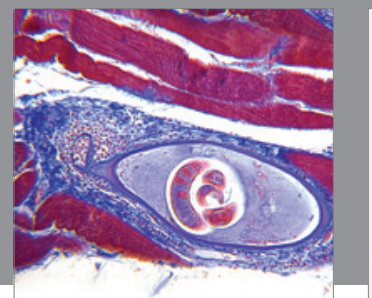

Gastroenterology

Research and Practice
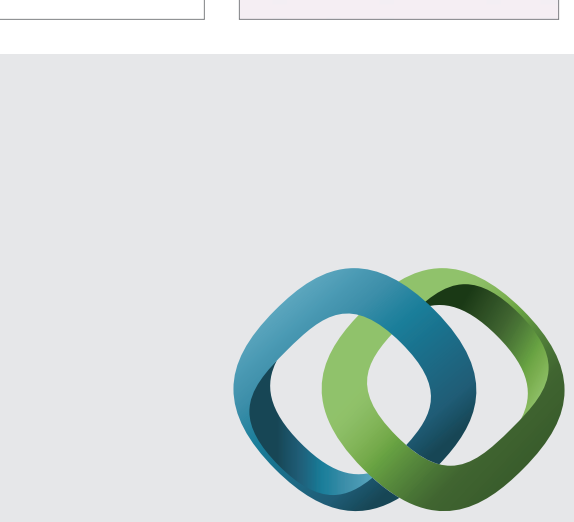

\section{Hindawi}

Submit your manuscripts at

http://www.hindawi.com
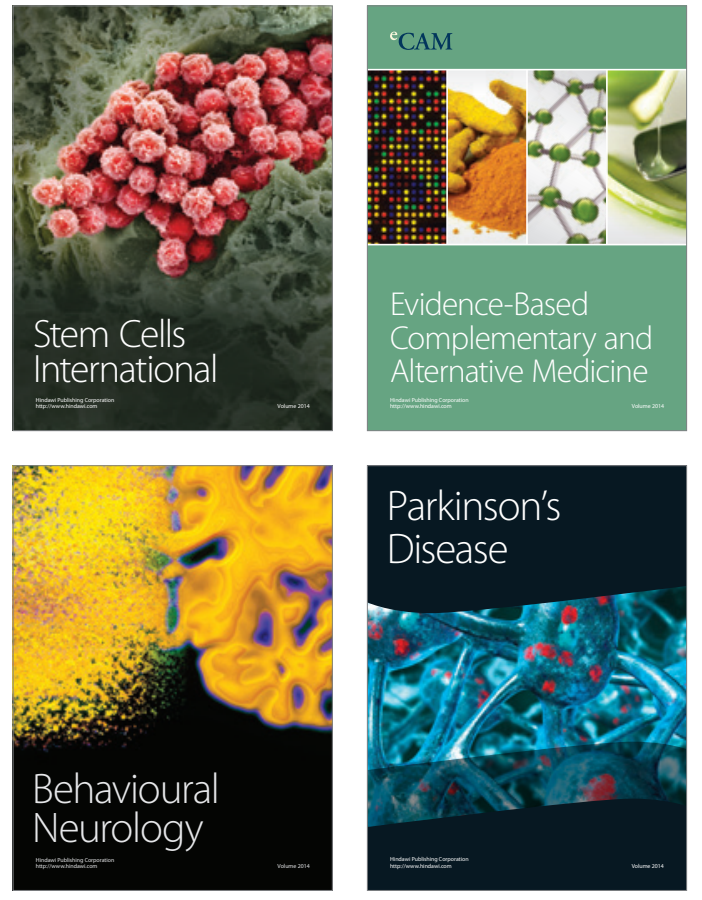
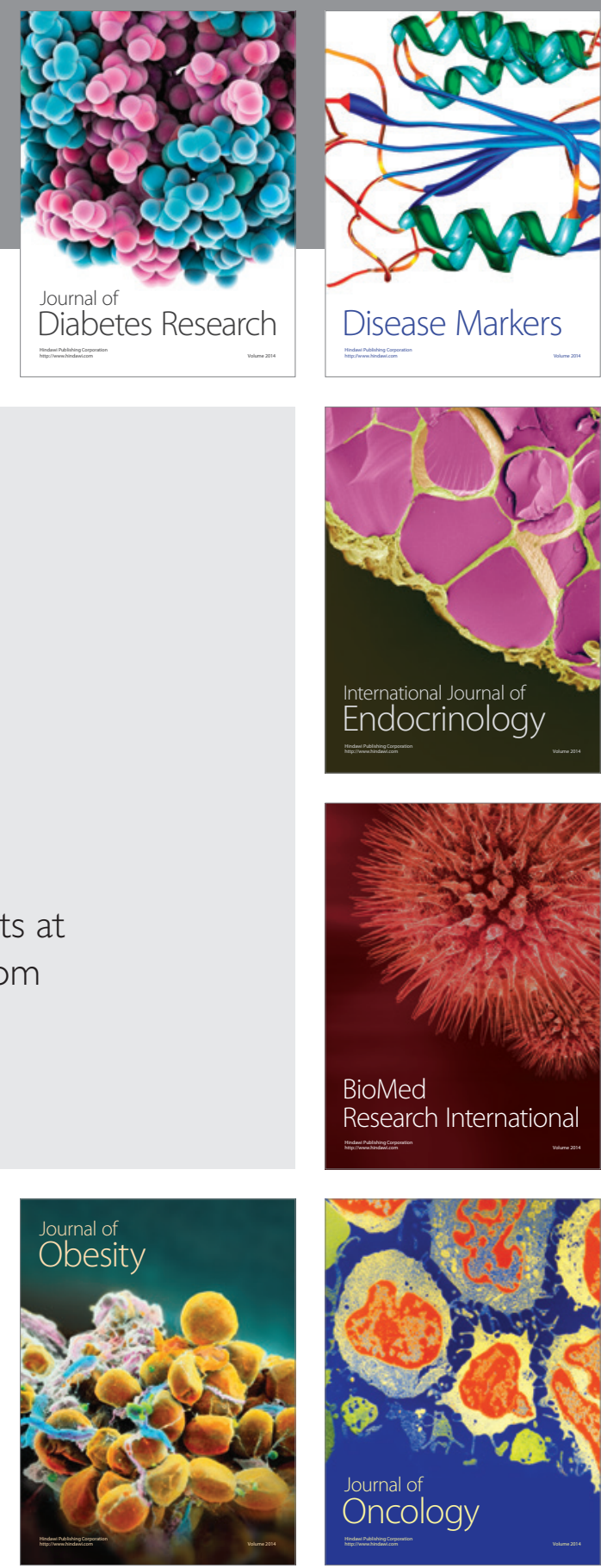

Disease Markers
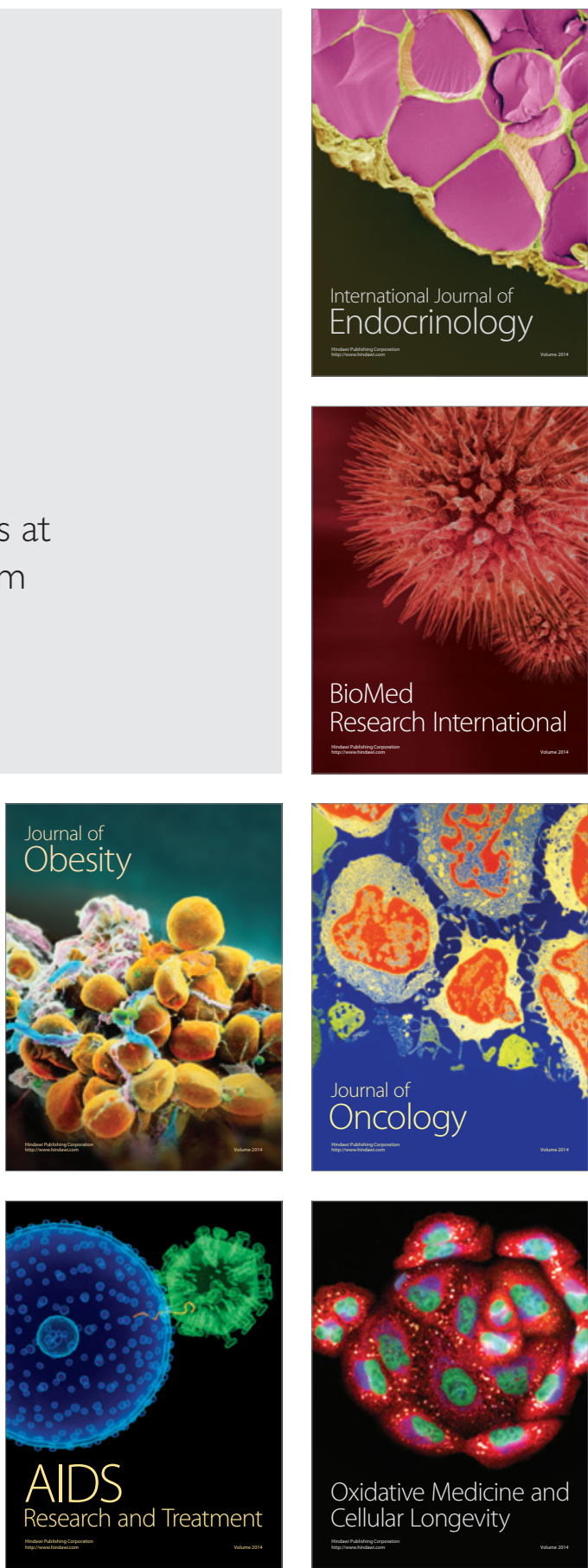